\title{
Primary Care Providers Believe That Comprehensive Medication Management Improves Their Work-Life
}

\author{
Kylee A. Funk, PharmD, BCPS, Deborah L. Pestka, PharmD, PhD, \\ Mary T. Roth McClurg, PharmD, MHS, Jennifer K. Carroll, MD, MPH, \\ and Todd D. Sorensen, PharmD
}

Purpose: In primary care, clinical pharmacists often deliver a service called comprehensive medication management (CMM). While research has identified that CMM positively influences most aspects of the Quadruple Aim, it is unclear how CMM — both the service and the role of the pharmacist—may influence the primary care provider's (PCP) clinical work, professional satisfaction, and burnout (described here as PCP's work-life). We aimed to identify how PCPs perceive CMM impacts their work-life.

Methods: Sixteen PCPs were interviewed. Interview questions centered on how CMM affects their work-life. After interviews were transcribed, a codebook was developed by 2 researchers and from the codes, themes were identified.

Results: PCPs spoke of the pharmacist being an added skillset and resource and a collaborative partner in caring for patients. They also described 7 outcomes of having CMM available that contribute to their work-life. These outcomes were: decreased workload, satisfaction patients are receiving better care, reassurance, decreased mental exhaustion, enhanced professional learning, increased provider access, and achievement of quality measures. Lastly, the PCPs described barriers and areas of opportunity related to $\mathrm{CMM}$.

Conclusion: Our findings suggest PCPs believe CMM, in general, positively affects their work-life. CMM's impact on PCPs aligns with many previously identified drivers of burnout and engagement among providers. These results shed light on how CMM may foster achievement of the Quadruple Aim. (J Am Board Fam Med 2019;32:462-473.)

Keywords: CMM, Job Satisfaction, Occupational Burnout, Pharmacists, Primary Health Care, Workload

Medication management services comprise a spectrum of patient-centered, pharmacist-provided, collaborative services that focus on improving patients' medication and health outcomes. ${ }^{1} \mathrm{~A}$ com-

This article was externally peer reviewed.

Submitted 17 December 2018; revised 29 March 2019; accepted 2 April 2019.

From the College of Pharmacy, University of Minnesota Collage of Pharmacy, Minneapolis, MN (KAF, DLP, TDS); Eshelman School of Pharmacy, University of North Carolina, Chapel Hill, NC (MTR); American Academy of Family Physicians National Research Network, Leawood, KS (JKC).

Funding: This work was funded by the The American College of Clinical Pharmacy (ACCP) and the ACCP Foundation Grant Enhancing Performance in Primary Care Medical Practice through Implementation of Comprehensive Medication Management.

Conflict of interest: none declared.

Corresponding author: Kylee A. Funk, PharmD, BCPS, College of Pharmacy, University of Minnesota College of Pharmacy, Room 50130 WDH, 1332A, 308 Harvard St SE, Minneapolis, MN 55455 (E-mail: kafunk@umn.edu). mon medication management service provided by many pharmacists is medication therapy management (MTM). However, to account for the comprehensive nature of the assessment, terminology has shifted toward comprehensive medication management (CMM). CMM is defined as, "The standard of care that ensures each patient's medications (whether they are prescription, nonprescription, alternative, traditional, vitamins, or nutritional supplements) are individually assessed to determine that each medication is appropriate for the patient, effective for the medical condition, safe given the comorbidities and other medications being taken, and able to be taken by the patient as intended." CMM is a defined process of care most often provided by a pharmacist and can take place in many settings, including primary care practices. ${ }^{3} \mathrm{Re}-$ search has demonstrated that CMM contributes to the Triple Aim-a goal that originated with the 
Institute for Healthcare Improvement, ${ }^{4}$ and is now endorsed by many organizations-by improving patients' health, ${ }^{5,6}$ enhancing patients' care experience, ${ }^{7,8}$ and decreasing health care costs. ${ }^{6,8}$

In recent years, the Triple Aim has been extended to a Quadruple Aim with a new goal added to "improve the work-life of health care providers." "Since current rates of workplace burnout are high among health care providers,${ }^{10}$ it is important to look at ways to achieve this fourth aim. Over half of all physicians are experiencing burnout, with family medicine and internal medicine having the highest rates of burnout of all specialties. ${ }^{11}$ Burnout is not just specific to physicians; nurse practitioners and physician assistants likely experience a similar rate of burnout. ${ }^{11}$ Furthermore, there are many negative effects of burnout, including decreased patient satisfaction, increased medical errors, and harmful personal effects for the provider. ${ }^{11}$ These negative effects all lead to increased health care costs; therefore, addressing provider wellbeing is imperative. $^{12}$

Emerging evidence suggests that organizational strategies may improve engagement and decrease burnout for health care providers. ${ }^{13-15}$ Team-based care is a promising example of one of these strategies. ${ }^{16,17}$ In addition to higher patient satisfaction and better clinical outcomes, teamwork in health care has demonstrated improved professional satisfaction among providers and staff. ${ }^{18-20}$ The importance of teamwork was emphasized in the Institute for Healthcare Improvement's Framework for Improving Joy in Work as a critical first step in achieving workplace satisfaction. ${ }^{14}$ While there is growing evidence demonstrating the benefit of CMM on patient outcomes, ${ }^{8,21}$ little is known about the impact of CMM on team members in primary care settings. While evidence suggests that teamwork contributes to professional satisfaction, to our knowledge, no work has been completed to specifically examine how CMM-both the service and the role of the pharmacist delivering $\mathrm{CMM}$-may impact primary care providers' (PCPs') clinical work, professional wellbeing, and burnout (henceforth described as their work-life). Therefore, this study aimed to identify how PCPs perceive the impact of CMM on their work-life.

\section{Methods}

This study was part of a larger CMM implementation and effectiveness project enrolling 36 pri- mary care clinics across 5 states. Sites included in the study were required to have established CMM services delivered by pharmacists embedded in the primary care clinic and acknowledge that they were offering CMM in a manner consistent with definitions outlined within the American College of Clinical Pharmacy Standards of Practice for Clinical Pharmacists ${ }^{22}$ and the $\mathrm{Pa}$ tient-Centered Primary Care Collaborative Comprehensive Medication Management Resource Guide. ${ }^{2}$ This study was approved by the University of North Carolina Institutional Review Board; the University of Minnesota Institutional Review Board determined that this assessment was not human subjects research and therefore did not require formal review.

\section{Participant Selection}

PCPs from 4 health systems in Minnesota were selected to participate in this study. PCPs were defined as physicians, physician assistants, and nurse practitioners. Clinics located in Minnesota were selected to participate in this study to facilitate the logistics of carrying out in-person interviews. The lead investigator (KAF) contacted the pharmacy managers of each health system requesting their participation in the study and requesting pharmacist assistance in identifying 2 to 8 PCPs to be interviewed. Eight pharmacists identified PCPs and assisted in scheduling interviews with 16 PCPs. Our goal was to conduct dyadic interviews; however, we did adapt our approach and conducted one-on-one interviews in situations where only 1 PCP could be present. Interviews were conducted until saturation was achieved (i.e., no new codes were emerging from the data).

\section{Data Collection}

We conducted 6 dyadic and 4 one-on-one interviews with $\mathrm{PCPs}$ at their respective clinic sites. Interviews took place between September and November 2017. Two members of the research team (KAF and DLP) were both present for the first 2 dyadic interviews to ensure that interview procedures were consistently conducted. From there, the same 2 investigators individually completed all remaining interviews. Depending on the time of day of the interview, participants were offered breakfast or a box lunch as an incentive for their participation. The interviews were semi-structured, lasted approximately 60 minutes, and were 
facilitated by 2 of the investigators (KAF and DLP). Interview questions (Appendix 1) centered around how CMM affects the PCP's clinical work, professional satisfaction, and burnout, as well as any possible limitations of CMM or areas of opportunity. In addition, PCPs also completed a notecard activity during the interview where they were asked to place notecards of various clinical functions on a 0 to 10 scale depending on how highly they felt the presence of CMM affected that function. They were then asked to describe why they placed their notecards where they did.

All interviews were audio recorded and transcribed by a commercial transcription agency.

\section{Data Analysis}

A pair of investigators with experience in research methods and prior experience leading qualitative analysis (KAF and DLP) independently coded the same 2 transcripts using an inductive approach. The investigators then met to compare codes to develop an initial codebook. The cycle of independently coding 2 transcripts, meeting to discuss coding, and revising the codebook as necessary occurred 2 additional times. Once both investigators agreed on a final codebook, the lead investigator coded all transcripts in NVivo (QSR International, 2017). As coding continued, any needed revisions to the codebook were discussed between the pair of investigators.

To enhance the validity of the findings, peer debriefing sessions were held with the other members of the research team in which they examined the developed codes and presented alternative perspectives to ensure that all areas had been considered during coding. ${ }^{23}$

\section{Results}

Characteristics of interviewed providers are presented in Table 1 . We considered whether the interview was dyadic or individual in our analysis, as dynamics could have altered the content of discussion. However, the content of the dyadic interviews did not differ from those of individual interviews and the same themes occurred.

Several themes emerged to describe the impact of CMM on PCPs' work-life. When speaking of the pharmacist, PCPs spoke of them contributing a unique and complementary knowledge and skillset, as well as being a collaborative partner in caring for
Table 1. Characteristics of the Primary Care Providers $(\mathrm{n}=16)$

\begin{tabular}{lc}
\hline Characteristic & N (\%) \\
\hline Gender & \\
Female & $12(75)$ \\
Male & $4(25)$ \\
Profession & \\
Physician & $13(81)$ \\
Physician assistant & $2(13)$ \\
Nurse practitioner & $1(6)$ \\
Years working with a pharmacist providing CMM & \\
$\quad$ services & \\
Less than 5 & $9(56)$ \\
5 to 10 & $7(44)$ \\
Greater than 10 & 0 \\
Years working as a primary care provider & \\
Less than 5 & $3(19)$ \\
5 to 10 & $2(13)$ \\
11 to 15 & $3(19)$ \\
16 to 20 & $1(6)$ \\
21 to 25 & $3(19)$ \\
26 to 35 & $2(13)$ \\
Greater than 35 & $2(13)$ \\
\hline
\end{tabular}

CMM, comprehensive medication management.

patients. They also described many positive outcomes of having CMM available that contribute to their work-life, as well as barriers and areas of opportunity that affect those outcomes. Themes were formed into a model presented in Figure 1. The themes are illustrated with quotations in Table 2 and discussed in detail below.

\section{Perception of the Pharmacist Providing CMM Collaborative Partner}

PCPs described that having a pharmacist providing CMM enabled them to work closely with another professional to care for patients and discuss care plans. The PCPs felt this relationship led them to feel supported, reassured, and less burned out. In addition, PCPs felt the pharmacist helped reinforce treatment decisions, which could lead to greater patient agreement and acceptance, taking some of the burden off their shoulders.

\section{Added Skillset and Resource}

PCPs expressed that the pharmacist's knowledge and skillset was complementary to their own. PCPs felt pharmacists were knowledgeable about evidence-based guidelines and medications making 
Figure 1. Provider perception of comprehensive medication management impact.

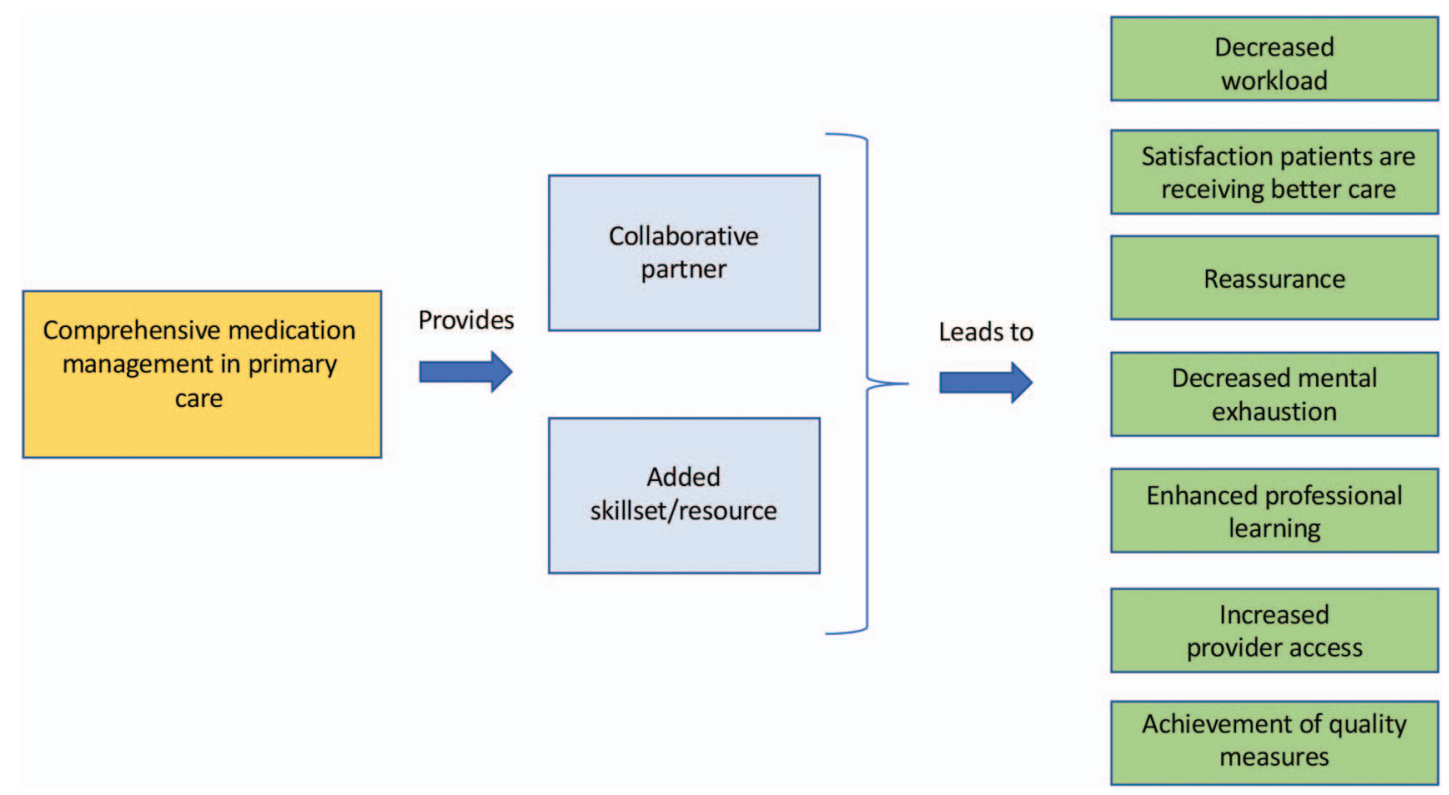

them a helpful resource for questions about medications, treatment options, prescription insurance coverage, etc. This, in turn, saved the PCP time because they did not have to look up this information themselves or wait for someone else who may require more time to find the answer. In addition, PCPs noted they can refer patients for CMM services if there are any medication-related questions or concerns. It was also mentioned that pharmacists can leverage their knowledge and skillset to create medication-related outreach materials for patients. Furthermore, pharmacists' understanding and ability to navigate the insurance system was a valuable and time saving resource for PCPs.

Because CMM is a unique assessment, PCPs noted that pharmacists often uncover medicationrelated problems that might have otherwise been missed. PCPs see this as time-saving because they do not have to collect this information during their visit and the information collected during a CMM visit can facilitate the PCP's visit with the patient. In addition, PCPs believed that the longer structure of the CMM visit allowed pharmacists to create a strong therapeutic relationship with the patient. This relationship facilitated the pharmacist's ability to obtain additional clinical information, details about medication use, and the history of the patient's condition(s) which was useful for the PCP when they conducted their visit and were creating a care plan.

\section{Impact of CMM on PCP's Work-Life}

Decreased Workload

PCPs spoke of how having CMM available meant that they could share some of their patient care and communication responsibilities. For example, pharmacists can assist with indirect care, such as phone calls to patients, addressing inbox messages, or refill requests. This frees up more time for the PCP and increases their satisfaction. PCPs often noted that when they know they can refer patients for CMM services, they are able to keep their own visits more concise and directed at medical care and they do not have to spend as much time reviewing and educating patients on their medications. As a result, PCPs commented that having CMM available may increase their availability to see more patients, and perhaps more same-day appointments, which leads to increased patient satisfaction.

\section{Satisfaction Patients Are Receiving Better Care}

PCPs that were interviewed described higher satisfaction because they know their patients receive more comprehensive care when they can rely on CMM services for certain aspects of care, such as addressing medication-related issues and providing medication education.

\section{Reassurance}

PCPs described the reassurance they felt when they had a partnership with a professional who provided 
Table 2. Emergent Themes and Example Quotation

\begin{tabular}{|c|c|}
\hline Theme & Example Quotation \\
\hline Collaborative partner & $\begin{array}{l}\text { "I think a lot of the burnout comes from all the multiple decisions you have to make in a day. } \\
\text { That can be exhausting. So just again, having someone you can collaborate with on some of } \\
\text { those things is great, so I think it reduces burnout. That collaboration absolutely reduces } \\
\text { burnout." (Participant 3) }\end{array}$ \\
\hline Added skillset and resource & $\begin{array}{l}\text { "I'll run things by [the pharmacist], med interactions or different questions, so having that } \\
\text { resource available makes my job easier and more fulfilling to be able to have someone to } \\
\text { ask questions." (Participant 14) }\end{array}$ \\
\hline Decreased workload & $\begin{array}{l}\text { "It does offload some of the work...it's another part of the team helping you take care of your } \\
\text { very complicated patients that's equivalent to a provider in terms of their knowledge of } \\
\text { medications, if not more; so it really helps take away some of that stress of managing all of } \\
\text { those chronically ill patients by yourself. (Participant 12) }\end{array}$ \\
\hline $\begin{array}{l}\text { Satisfaction patients are receiving } \\
\text { better care }\end{array}$ & $\begin{array}{l}\text { "Just their expertise makes me feel satisfied, because I feel my patients are getting the highest } \\
\text { quality [care]. I think it feels so unsatisfying when you don't know something for a patient, } \\
\text { so even if I'm not the one solving it for them, to be able to have a resource nearby makes } \\
\text { me feel satisfied, because I feel like I can see that my patients are getting quality care even } \\
\text { if it's not a hundred percent from me." (Participant 2) }\end{array}$ \\
\hline Reassurance & $\begin{array}{l}\text { "I've been around long enough to see not only burnout as far as a chronic condition, just } \\
\text { wearing people down, and you see that, but what you also see is an occasional catastrophic } \\
\text { event, lawsuit, loss of license, really horrific things to patients and to providers. I think } \\
\text { there's a two-way thing on this and that's part of why I wanted to be able to talk about this } \\
\text { openly is the major effect is it reduces that risk." (Participant 10) }\end{array}$ \\
\hline Decreased mental exhaustion & $\begin{array}{l}\text { "A lot of the patients that [CMM] sees are really complex and they need so much time, and } \\
\text { they have so much information, and I think it's just even if I could spend the extra time, it } \\
\text { just feels like such a mental burden and sometimes an emotional burden, that it feels so } \\
\text { nice to either know there's another set of eyes on this patient or oh, this person can handle } \\
\text { this one chunk for me." (Participant 2) }\end{array}$ \\
\hline Professional learning & $\begin{array}{l}\text { "I'm constantly learning things from [CMM]. Especially with the diabetes, they're very } \\
\text { knowledgeable with all the new things coming out, all the little tricks, or ways to help } \\
\text { patients take meds [medications] easier, so I think it plays a lot into compliance. I think it } \\
\text { makes me a better doctor, hearing those things as we work together." (Participant 1) }\end{array}$ \\
\hline $\begin{array}{l}\text { Increased patient access to } \\
\text { providers }\end{array}$ & $\begin{array}{l}\text { "My patients' biggest complaint is that they can't get in to see me, so being able to see } \\
\text { [CMM] and save some other appointments for myself for my more complicated patients is } \\
\text { a huge help." (Participant 14) }\end{array}$ \\
\hline Achievement of quality measures & $\begin{array}{l}\text { "We're constantly graded on quality, like are we meeting certain standards for diabetes, high } \\
\text { blood pressure, all these things, and having [CMM] as another resource for our patients, } \\
\text { another place, another person that can fine-tune some things for us indirectly, helps our } \\
\text { quality numbers as a provider, but also our whole clinic when we look at it. To make sure } \\
\text { people are reaching their goals that they need to be at number-wise." (Participant 1) }\end{array}$ \\
\hline Barriers to CMM & $\begin{array}{l}\text { "There are sometimes barriers to having [pharmacists providing CMM], like not knowing if } \\
\text { patients are covered by them or when patients aren't covered by them [i.e. insurance } \\
\text { coverage for CMM services]. But that's not a disadvantage; it's just more of a barrier to } \\
\text { care." (Participant 2) }\end{array}$ \\
\hline Areas of opportunity & $\begin{array}{l}\text { "Just }[\mathrm{CMM}] \text { being here five days a week. Just that consistency would be nice. Then it's a } \\
\text { service that you can count on in a way that is predictable." (Participant 12) }\end{array}$ \\
\hline
\end{tabular}

CMM, comprehensive medication management.

support in caring for patients. In addition, PCPs described feeling more confident in their treatment recommendations if they were able to consult with a pharmacist. Stress around potential malpractice claims was also decreased for some PCPs through collaboration with CMM services.

\section{Decreased Mental Exhaustion}

PCPs felt that CMM decreased some of the pressure and mental/emotional burden of taking care of complex patients. They added that the assessment conducted during a CMM visit oftentimes helped to simplify and better organize the patient's needs, so that their unresolved needs were easier for the PCP to address.

\section{Enhanced Professional Learning}

By having a pharmacist providing CMM present, PCPs spoke of the additional medication, medication management, and disease state management education they acquire. Professional learning may occur when the PCP asks a drug information question, reviews a CMM note, or attends a more formal training session from the pharmacist. 


\section{Increased Patient Access to Providers}

PCPs described that having CMM available increased access to care through 2 mechanisms: (1) patients can schedule a CMM visit for a medication-related need instead of scheduling a visit with their PCP, and (2) when the first scenario occurs, the PCP has more availability to see other patients. In addition, many patients do not have a copay to see a pharmacist for CMM services, which leads to more adherence to attend CMM visits and patients are generally able to attend a CMM visit in a timely manner.

\section{Achievement of Quality Measures}

PCPs recounted how they often work with pharmacists providing CMM to help them achieve clinic quality measures and that the pharmacist may provide additional strategies to achieve quality measures (e.g., phone calls, outreach letters). It was also noted that pharmacists often help PCPs keep track of quality measures and make sure patients are meeting goals. The PCPs discussed how they experienced increased satisfaction with sharing the responsibility in working toward improved quality measures.

\section{Factors Affecting the Impact of CMM on PCPs' Work- Life}

Barriers to CMM

There were a number of factors PCPs noted that hinder or limit the effect of CMM on their worklife. For example, not knowing which patients have insurance coverage that will reimburse for CMM limits the amount of referrals that PCPs make. In addition, PCPs noted there may be instances where a trusting relationship does not exist between the PCP and the pharmacist, and this would present a barrier for referrals and collaboration. In addition, some patients, because of their lack of awareness of CMM, may be reluctant to see a pharmacist. Furthermore, the PCPs discussed hypothetical disadvantages of working with a pharmacist providing CMM that they personally had not experienced, but imagined could occur. These hypothetical disadvantages included loss of PCP autonomy, a concern of increased liability if care decisions were made by another provider, and the thought that patients may forego their PCP visits if they feel they are receiving the care they need during their CMM visit.
Areas of Opportunity

Finally, PCPs offered a number of suggestions for ways in which CMM services could be modified to improve PCPs' work-life. For example, many clinics do not have a full-time pharmacist providing CMM, but many PCPs expressed a strong desire for greater presence of CMM in their clinic. PCPs also felt opportunities exist for pharmacists to identify more patients from PCPs' schedules and for patients to self-refer for CMM services. In addition, PCPs discussed specific patient populations that would benefit from additional CMM collaboration, such as patients needing chronic pain management.

\section{Discussion}

Our findings demonstrate that PCPs view pharmacists providing $\mathrm{CMM}$ as a collaborative partner that offers a complementary skillset they can rely on for CMM services and knowledge of medications. Having CMM available leads to several outcomes that positively affect PCPs' work-life. These outcomes are negatively affected by potential barriers to CMM delivery, but areas of opportunity exist to enhance or expand CMM which may further improve PCPs' work-life.

Our current work builds on studies which have demonstrated PCP satisfaction with the CMM model of care. For instance, physicians feel having a pharmacist in their clinic makes the physician more efficient, ${ }^{24-26}$ able to provide better care, ${ }^{25,27}$ more knowledgeable, ${ }^{25,27}$ more confident about prescribing, ${ }^{26}$ more effective in treating challenging patients ${ }^{26}$ and, in general, makes their job easier. ${ }^{24}$ Despite ties to previous literature, the provider experience with CMM, as it relates to work-life, had not been defined.

There are many connections between the themes we identified in this study and the $7 \mathrm{key}$ drivers of burnout and engagement described by Shanafelt and colleagues $^{10}$ (Table 3). The first driver of "workload and job demand"10 is one that the providers in our study noted CMM helped to alleviate. Workload is commonly cited to contribute to burnout and studies have demonstrated that increased rates of burnout are linearly associated with increased time spent at home on work-related tasks. ${ }^{11}$

Another driver of burnout and engagement that Shanafelt et al. ${ }^{10}$ noted was the ability to find meaning in work. This can be completed through 
Table 3. Connection between Previously Identified Drivers of Burnout and Impact of CMM on Providers

\begin{tabular}{lc}
\hline $\begin{array}{l}\text { Seven Drivers of Burnout } \\
\text { and Engagement }{ }^{11}\end{array}$ & $\begin{array}{c}\text { Related Theme(s) from Provider } \\
\text { Perception of CMM }\end{array}$ \\
\hline
\end{tabular}

\begin{tabular}{ll}
\hline Workload and Job & $\bullet$ Decreased workload \\
Demands & $\bullet$ Achievement of quality measures
\end{tabular}

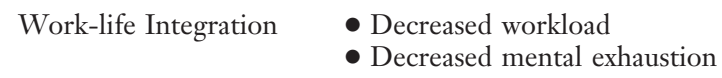

$\begin{array}{ll}\text { Social Support and } & \bullet \text { Collaborative partner } \\ \text { Community at Work } & \bullet \text { Reassurance }\end{array}$

$\begin{aligned} \text { Efficiency and Resources } & \bullet \text { Added skillset/resource } \\ & \text { - Decreased Workload } \\ & \bullet \text { Increased provider access }\end{aligned}$

$\begin{array}{cc}\begin{array}{c}\text { Organizational Culture } \\ \text { and Values }\end{array} & \begin{array}{c}\text { Our findings do not connect to this } \\ \text { driver }\end{array} \\ \text { Control and Flexibility } & \begin{array}{c}\text { Our findings do not connect to this } \\ \text { driver }\end{array}\end{array}$
Illustrative Quotation from CMM Interviews

"Actually, it just gives me another resource for complicated medical management issues for questions about new meds [medications], for questions. I mean, when they're in your care team, it is one other person on your team that helps you take care of the patient. Sometimes I feel like I might get less even questions from nurses, because [the pharmacist] is available for nurses to ask questions to. So it frees me up for other things and makes my day for sure more efficient because they're there to help offload some of the medicine questions, for me as well as for other staff." (Participant 12)

"If sometimes we have this chronic condition that we can pass on to [the CMM service] and they can work on that while we're addressing a couple of other things with the patients, that's satisfying, but it also helps us stay moving throughout our day. If we can pass the patient off to them and we can keep seeing other patients and we're not stuck on a particularly problematic issue that we don't really have time for that day, then I get to go home and be with my family and that's really nice. So yeah, they're also very helpful in that situation and that's very good for professional satisfaction.” (Participant 4)

"I feel like with [the pharmacist] it's just a nice, really a collegial, kind of ... Sometimes we're both doing the same thing, although they know a ton more about the medicines than I do. But I might know more about something else than they, or something; but it's a really collegial sort of sharing, and for me personally, that's fulfilling, and that makes the day nicer and brighter and positive." (Participant 12)

"Again, research has shown in multiple clinical scenarios where a follow up from the clinic helps with these sorts of things, but I can just take that off my plate and trust that it will get done and it will get done well, and in perhaps an easier way for the patient, because they don't necessarily need to come in for a one-on-one visit with me then in addition. They can do that with the [CMM] pharmacist in clinic, or do a phone consultation as well, and not have any more lost time from work for the patient. Again, it's not on my time, after hours, adding to my day." (Participant 15)

"Just [the pharmacists'] expertise makes me feel satisfied, because I feel my patients are getting the highest quality. I think it feels so unsatisfying when you don't know something for a patient, so even if I'm not the one solving it for them, to be able to have a resource nearby makes me feel satisfied, because I feel like I can see that my patients are getting quality care even if it's not a hundred percent from me." (Participant 2) was apparent both of these factors contributed to their own meaning in work. The ability to provide high quality care to patients has been tied to increased professional satisfaction, ${ }^{19}$ and in our study, PCPs noted that working collaboratively with the pharmacist provided them with professional satisfrom pharmacists providing CMM and also for their personal collaboration with the pharmacist. It 
faction. In addition, PCPs identified that having CMM services available fostered professional learning, which likely also strengthened their personal sense of meaning from work. In fact, studies have demonstrated that engaging in skill development can be protective against burnout. ${ }^{28}$

Efficiency and resources have been identified as an additional driver of burnout and engagement. ${ }^{13}$ This could also be influenced by the theme of decreased workload that was observed in this study. Many PCPs discussed that their visits were more efficient with patients after they had been seen by a pharmacist providing CMM because they could direct their attention at medical concerns or problems rather than medication-related problems. In addition, all participants spoke of the utility and value of having the pharmacist available as a resource.

Lastly, Shanafelt and colleagues ${ }^{13}$ suggest that collegiality can improve the driver of social support and community at work. The PCPs in this study related that the themes of a collaborative partner and reassurance contributed to their sense of support at work. Furthermore, the PCPs' decreased mental exhaustion was attributed, in part, to having a partner to engage in shared decision making. The concept of participatory decision making among team members has been identified as a way to decrease burnout in a patient-centered medical home setting ${ }^{28}$ and seems to have contributed to the provider satisfaction of working with pharmacists in our study. In addition, team-based health care has been shown to reduce clinician burnout. ${ }^{17}$

PCPs discussed several opportunities for improving collaboration and pharmacist visit volume. Many clinics do not have a full-time pharmacist providing CMM, but rather use a pharmacist part time based on the clinic size and need. In our interviews, PCPs discussed their desire for a fulltime, on-site pharmacist providing CMM to improve collaboration and workflow integration. Second, PCPs discussed the importance of increasing PCP referral for CMM as a strategy to enhance patient care access and outcomes. A third opportunity that was suggested was to include CMM as standard of care for more patient groups, such as chronic pain.

In many cases, the primary barrier to addressing the desire to increase the presence of a pharmacist providing CMM or expanding the amount of time dedicated to the practice is rooted in financial considerations. In most regions of the country, the opportunity to directly bill for CMM services is limited. Thus, from a cost and revenue perspective, many administrators do not choose to invest in this collaborative practice. However, the themes identified in this study shed light on how one can build a value proposition for collaborative CMM services using the Quadruple Aim as a framework. Participants in this study highlighted the net positive impact of CMM on quality of care, which is consistent with other research. ${ }^{5,6}$ The overall themes of this study point to a positive impact on primary care provider experience. Other studies have highlighted a positive impact on $\operatorname{cost}^{6,8}$ and patient experience, ${ }^{7,8}$ the final 2 components of the Quadruple Aim. Thus, there is a potential opportunity to facilitate expansion of CMM through preparing both primary care providers and pharmacists to frame the value equation of CMM away from the basic accounting principles of feefor-service to one that takes into account positive benefits across the dimensions of health care quality, costs, patient experience and provider work-life.

This study has limitations. By design, we only interviewed PCPs from clinics in Minnesota. Although this created a participant pool with a rich understanding and longer collaboration with pharmacists who provide services consistent with standards established for CMM, it is possible that their views may not be representative of all PCPs. In addition, the PCPs who volunteered for the study were likely those who collaborated more closely with pharmacists and had a positive experience. An important consideration is that the pharmacists providing CMM at participating clinics had a consistent practice model and take responsibility for resolving patients' medication therapy problems. This is different from some pharmacist practices which may be only consulting or limited to certain diseases (e.g., anticoagulation, diabetes management). Several of the themes that emerged in our study may not be replicated when investigating PCPs' experience with pharmacists who are embedded in a primary care clinic, but provide services other than CMM. For instance, the sense of having a collaborative partner would likely be lost if the pharmacist did not accept the personal responsibility of resolving medication-related problems for the patient. 
Future research is needed to look beyond CMM's impact at the level of the PCP-pharmacist relationship and investigate CMM's impact on the organization. We identified 7 themes that illustrate how the presence of CMM affects PCP work-lives. However, it is likely that these outcomes have farther reaching effects to the organization. For instance, it is already clear that burnout leads to negative patient outcomes ${ }^{11}$ and worsened financial prospects for health care organizations, ${ }^{12}$ but at this point, it is unclear if the integration of CMM services and the resulting influence on the providers impacts those organizational outcomes. As more health care organizations seek to improve value in health care, it will be important to consider the impact that CMM collaborations-and more broadly interprofessional relationships-have on all aspects of the Quadruple Aim.

The authors acknowledge Amanda Brummel, PharmD, BCACP for her valuable feedback. In addition, the authors wish to acknowledge all the participating primary care providers, pharmacists, and the entire CMM in Primary Care Team for their insights on this project.

To see this article online, please go to: http://jabfm.org/content/ 32/4/462.full.

\section{References}

1. Joint Commission of Pharmacy Practitioners. Medication management services (MMS) definition and key points. Available from: https://jcpp.net/wp-content/ uploads/2018/05/Medication-Management-ServicesDefinition-and-Key-Points-Version-1.pdf. Accessed March 25, 2019.

2. Patient-Centered Primary Care Collaborative (PCPCC). The patient-centered medical home: Integrating comprehensive medication management to optimize patient outcomes resource guide. 2 nd ed. Washington, DC: PCPCC, 2012. Available from: www.pcpcc.org/sites/default/files/media/medmanagement.pdf. Accessed May 17, 2018.

3. The patient care process for delivering comprehensive medication management (CMM): Optimizing medication use in patient-centered, team-based care settings. CMM in primary care research team. July 2018. Available from: http://www.accp.com/cmm_care_process. Accessed Nov 11, 2018.

4. Berwick DM, Nolan TW, Whittington J. The Triple Aim: Care, health, and cost. Health Affairs 2008; 27:759-769.

5. Bunting BA, Smith BH, Sutherland SE. The Asheville Project: Clinical and economic outcomes of a community-based long-term medication therapy management program for hypertension and dyslipidemia. J Am Pharm Assoc 2008;48:23-31.
6. Brummel A, Lustig A, Westrich K, et al. Best practices: Improving patient outcomes and costs in an ACO through comprehensive medication therapy management. J Manag Care Spec Pharm 2014;20: 1152-1158.

7. Kim S, Martin MT, Pierce AL, et al. Satisfaction with medication therapy management services at a university ambulatory care clinic. J Pharm Pract 2016;29:199-205.

8. Ramalho de Oliveira D, Brummel AR, Miller DB. Medication therapy management: 10 years of experience in a large integrated health care system. J Manag Care Pharm 2010;16:185-195.

9. Bodenheimer T, Sinsky C. From Triple to Quadruple Aim: Care of the patient requires care of the provider. Ann Fam Med 2014;12:573-576.

10. Shanafelt TD, Hasan O, Dyrbye L, et al. Changes in burnout and satisfaction with work-life balance in physicians and the general US working population between 2011 and 2014. Mayo Clin Proc 2015;90: $1600-1613$.

11. Dyrbye LN, Shanafelt TD, Sinsky CA, et al. Burnout among health care professionals: A call to explore and address this underrecognized threat to safe, high-quality care. NAM Perspectives. 2017. Discussion Paper. Washington, DC; National Academy of Medicine, July 5, 2017. Available from: https://

nam.edu/burnout-among-health-care-professionalsa-call-to-explore-and-address-this-underrecognizedthreat-to-safe-high-quality-care. Accessed June 21, 2018.

12. Shanafelt T, Goh J, Sinsky C. The Business case for investing in physician well-being. JAMA Intern Med 2017;177:1826-1832.

13. Shanafelt TD, Noseworthy JH. Executive leadership and physician well-being: Nine organizational strategies to promote engagement and reduce burnout. Mayo Clin Proc 2017;92:129-146.

14. Perlo J, Balik B, Swensen S, et al. IHI Framework for Improving Joy in Work. IHI White Paper. Cambridge, MA: Institute for Healthcare Improvement; 2017.

15. Card AJ. Physician burnout: Resilience training is only part of the solution. Ann Fam Med 2018;16: 267-270.

16. Grumbach K, Bodenheimer T. Can health care teams improve primary care practice? JAMA 2004; 10;291:1246-1251.

17. Smith CD, Balatbat C, Corbridge S, et al. Implementing optimal team-based care to reduce clinician burnout. NAM Perspectives. Discussion Paper. Washington, DC: National Academy of Medicine; 2018. Available from: https://nam.edu/implementing-

optimal-team-based-care-to-reduce-clinician-burnout.

18. Willard-Grace R, Hessler D, Rogers E, et al. Team structure and culture are associated with lower burn- 
out in primary care. J Am Board Fam Med 2014;27: 229-238.

19. Sinsky CA, Willard-Grace R, Schutzbank AM, et al. In search of joy in practice: A report of 23 highfunctioning primary care practices. Ann Fam Med 2013;11:272-278.

20. Mickan SM. Evaluating the effectiveness of health care teams. Aust Health Rev 2005;29:211-217.

21. Viswanathan M, Kahwati LC, Golin CE, et al. Medication therapy management interventions in outpatient settings: A systematic review and meta-analysis. JAMA Intern Med 2015;175:76-87.

22. American College of Clinical Pharmacy. Standards of practice for clinical pharmacists. Pharmacotherapy 2014;34:794-797.

23. Creswell JW. Qualitative inquiry and research design: Choosing among five traditions. Qualitative inquiry and research design: choosing among five traditions. 3rd ed. Los Angeles, CA: Sage Publications, Inc; 2013.
24. Moreno G, Lonowski S, Fu J, et al. Physician experiences with clinical pharmacists in primary care teams. J Am Pharm Assoc 2017;57:686-691.

25. Kozminski M, Busby R, McGivney MS, et al. Pharmacist integration into the medical home: Qualitative analysis. J Am Pharm Assoc 2011;51:173-183.

26. Pottie K, Farrell B, Haydt S, et al. Integrating pharmacists into family practice teams physicians' perspectives on collaborative care. Can Fam Physician 2008;54:1714-1717.e5.

27. Williams CR, Woodall T, Wilson CG, et al. Physician perceptions of integrating advanced practice pharmacists into practice. J Am Pharm Assoc 2018; 58:73-78.e2.

28. Helfrich CD, Dolan ED, Simonetti J, et al. Elements of team-based care in a patient-centered medical home are associated with lower burnout among VA primary care employees. J Gen Intern Med 2014; 29(Suppl 2):S659-S666. 


\section{Appendix: Interview Guide}

Interview Guide-PCP Perception CMM Services

[Note: While all pharmacists in this study practice CMM, they identify as MTM pharmacists within their clinics and it is the term nonpharmacy providers are most familiar with. Therefore, the term MTM was used throughout interviews].

Interviewer: Thank you for taking the time to talk with me today. At your clinic, you work with a pharmacist that provides MTM. We want to understand how having MTM services available to you and your patients impacts your daily work and also how MTM services may impact your professional satisfaction. We plan to use your responses to understand how best to maximize pharmacists' contributions in clinics.

Before we begin this interview, I would like to take a few minutes to highlight a few key points.
This interview will last around 60 minutes and, if it is okay with you, I would like to record our conversation. This is to help my note taking because people say very helpful things in these conversations and I just cannot write it all down fast enough. Your name will not be attached to the final results and only the research team will have access to the files. We welcome all your ideas and experiences. There are no right or wrong answers. In addition, if you do not feel comfortable answering any question feel free to say so and I will move on to the next question.

Throughout this conversation, we will be referring to MTM. Although you may have experience with a specific pharmacist, we are hoping to focus more on the service and what the pharmacist does versus the pharmacist themselves.
How does having MTM available to you affect your day-to-day work?

We have some notecards here with some common clinical functions or clinical descriptions. * What we'd like you to do is place these notecards on the 0 to 10 scale we gave you-a 10 means having MTM available greatly affects what's on the notecard and a 1 means MTM has no effect. There are no right or wrong answers, we're just curious what your perspectives are.

We all know that day-to-day tasks can affect professional satisfaction. Professional satisfaction is often driven by the ability to provide quality care and "includes a high level of [provider] work life satisfaction, a low level of burnout, and a feeling that medical practice is fulfilling." How does having MTM at your clinic positively and/or negatively affect your professional satisfaction?

For example, conversations about medication management may improve some PCP's satisfaction due to their interest in the subject matter, but may decrease some PCP's satisfaction due to the time these conversations take away from their other day-to-day tasks.

Now we would like to talk a little bit about burnout.

How has having MTM at your clinic positively and/or negatively affected burnout.

Are there any additional things that you would like to share about MTM services and how the presence of these services affect you and the service you provide to patients?
- What are some of the advantages of having MTM available to you?

- What are some of the disadvantages or limitations of MTM?

- What value, if any, does MTM bring to your work as a provider?

- How did you decide on where you placed the notecards?

- Are there additional notecards that aren't here that should be?

- If so, how does the MTM service affect those functions?

- What are the specific aspects of MTM that affect your job satisfaction?

- Are there things MTM is not doing, but could do to increase satisfaction? If so, what?

- What are the specific aspects of MTM that affect burnout for you?

- Are there things about MTM that could be changed to decrease feelings of burnout? If so, what? 
Suppose you were in charge of the MTM service and could do whatever you wanted to so that MTM reduced PCP burnout. What would you change?
- [If administrative tasks are brought up]: Let's say we have a pharmacy technician who can complete those administrative tasks. What else would you change?

*Notecards read:

- Gathering and reviewing information for my patients

- Recommending and discussing treatment options with my patients

- Documenting my patient visits

- Communicating with my patients

- Working towards and achieving the clinic's quality improvement initiatives with my patients

- Payment the clinic receives for my patients (e.g. RVUs I bill)

- Other ___ (please fill in the blank) 